\title{
SEM PALAVRAS NA PONTA DA LÍNGUA: SAÚDE MENTAL COLETIVA, PEDAGOGIA E GAGUEIRA
}

\author{
NO WORDS BY HEART: MENTAL HEALTH CONFERENCE, PEDAGOGY \\ AND STUTTERING
}

\section{Gisele Vicente}

Pedagoga e Especialista em Saúde Mental Coletiva pela Universidade Federal do Rio Grande do Sul UFRGS/EDUCASAÚDE.

Email: gisevicente@gmail.com

\section{Luciano Bedin da Costa}

Docente na Universidade Federal do Rio Grande do Sul - UFRGS e PósGraduação em Psicologia Social e Institucional da UFRGS.

Email: bedin.costa@gmail.com

\section{Resumo}

Este artigo reescreve um trabalho de conclusão de residência multiprofissional em saúde mental coletiva. Escrita em narrativas de percurso, pretende, em processos de desmanches de palavras, provocar um gaguejar da língua em saúde mental coletiva. Trabalho feito em muitas mãos, de encontros com Roland Barthes e sua abordagem acerca da teatralização da língua, com Manoel de Barros a escovar palavras para ouvir seu primeiro sussurrar e Jorge Larosa com sua ideia de sujeitos enquanto viventes de palavras. Apresenta, sem palavras na ponta da língua, a pedagogia, a saúde coletiva e seus gaguejares. Com palavras a titubear trajetos em estar residente, perguntar: qual o lugar da pedagogia na saúde mental coletiva? Em atos de saúde, a pedagogia chega nova sem ser novidade: ela chega entre espaços de não estar. De pensamentos nômades, uma pedagogia em saúde mental coletiva pode emergir de práticas mestiças, do gaguejar de palavras, do trincar da língua.

Palavras-chave: Saúde Mental Coletiva; Pedagogia; Linguagem. 


\section{Abstract}

This article is a new point of view of the work developed in the collective mental health residency. The route narratives were used to show miscarriages processes of words, and to crack collective mental health concepts. This paper was wrote by many hands as well as inspirations as Roland Barthes' dramatizing knowledge, Manoel de Barros' unpretentious poetry and Jorge Larosa's idea about subject, which is understood as living word. Even without completeness, it dares to show pedagogy, public health and their cracks. There is some hesitation, even after cross the path, but the question should be asked: what place has the Pedagogy in Collective Mental Health? The Pedagogy was transformed, but the usual health view can't see anything new, there is no assurance about the place in each one shall occupy. However, crossbred practices, stutter and cracks might bring out a peregrine thought to Collective Mental Health.

Keywords: Collective Mental Health; Words; Pedagogy.

\section{Prólogo}

Além deste prólogo, este trabalho é dividido em quatro partes, seguidas de um epílogo. Cada qual funciona como uma espécie de maquinador de possíveis, em se falando da pedagogia exposta ao campo da saúde mental. A partir da convicção de que as palavras produzem sentido, criam realidades $e$, às vezes, funcionam como potentes mecanismos de subjetivação, ${ }^{1}$ perceber e escutar nossas palavras em saúde mental coletiva é dar sentido ao que somos e ao que nos acontece. Não se trata, portanto, de definir e tampouco circunscrever lugares. Pelo contrário, é na aposta de uma variação e titubeio da língua que nos colocamos a falar a respeito da relação entre pedagogia e saúde coletiva.

Neste texto, com o que conseguimos enunciar a partir de nossas experiências, a pedagogia na saúde mental coletiva anda a murmurar. Balbucia um linguajar tentando marcar alguma entonação. Então a própria língua de uma pedagogia põe-se a gaguejar.

De pensamentos nômades, uma pedagoga se desequilibra e cambaleante compõem palavras: "gaga de nascença e, no entanto, tinha algo a dizer." 2:123 A pedagoga quer saber, será possível fazer nossa língua gaguejar? Ela entende que coletivos multiprofissionais fazem a língua deslizar, bifurcar e variar em cada uma de suas palavras.

Pensar quais palavras compõem a saúde mental coletiva é exercício desta escrita. Exercício que se faz de um texto que "já não tem a frase por modelo; é amiúde um potente jato de palavras." ${ }^{\text {3:13 }} \mathrm{Em}$ jatos de palavras, um tanto descontínuo, pensado para ser simples, de poucas palavras, esta escrita não conclui: ele escuta.

Bocas de ouvir palavras em coletivos multiprofissionais para com pés de se olhar, perceber quais realidades atualizamos com nossas palavras. Assim, na proposição de práticas de desmanche de palavras, esta escrita convida a fazer gaguejar nossos conceitos em saúde mental. Entre frases, enunciados, referências, experiências, imagens e fabulações, cultivar espaços vazios para a ausência de palavras.

\section{Parte I}

Nada existe, exceto a língua. ${ }^{3: 14}$

Tenho muitas palavras dentro do olho. Aprendi a dialogar com as águas, ainda que 
não soubesse bem a língua das marés. Contudo que soletrassem mares melhor que mim. Palavras conchas de clamores antigos incrustados em pedras de murmúrios ininteligíveis. Acho que nunca tive palavra na ponta da língua, que saísse fácil. Palavra em mim é como soco na boca do estômago. Palavra morna, doce, bem intencionada também têm impacto: palavras blocos gessos ósseos discursos que permeiam nossos manicômios virtuais, nossas desinstitucionalizações institucionalizadas, nossos jeitos de conduzir, de cuidar, de dizer e reconhecer o saudável, etc. Eu sabia que "as palavras possuem no corpo oralidades remontadas e muitas significâncias. Eu queria então escovar as palavras para escutar o primeiro engasgar de cada uma. Para escutar os primeiros sons, mesmo que ainda dígrafos." 4:21 O escovar das palavras da pedagogia na saúde mental pode bem fazer gaguejar nossos conceitos de saúde. A pedagogia pode atualizar este movimento multiprofissional, pelo seu caráter de coletivo, de cidade, de fluxo, de pensamento. $O$ contrário também pode acontecer: a saúde coletiva e suas diferentes profissões refazem a pedagogia, desfiguram a pedagoga que, com fios diversos tece para si muitas máscaras.

Escovar palavras. Como o arqueólogo sentado na terra a escovar osso por amor. Escovar o texto por prazer, entregar-se a fruição da palavra pelo gozo, repensar a língua e se possível desmontá-la: porque fomos nós que a inventamos! Estar como alguém que, num processo de raspagem da palavra dita em saúde mental faz desse exercício, também, os modos, processos e dinâmicas para a efetivação da prática coletiva. Seria então, todo movimento de fazer fissuras, pelo gosto de tirar em lascas todo excesso que a palavra carrega.

Que falasse a gaguejar conceitos talvez ouvisse a encenação de um aparecimento/ desaparecimento da língua. Assim, para cada palavra em movimento um tropeço repentino. Algo de supetão. Pé pedra rosto chão. Um desatino. Um apagão sem aviso. Um lapso. Um circuito eletrocardiográfico. Um jogo de aparecer e desaparecer. Não queremos palavra nova o tempo todo. Ela vem quando em bons encontros, nos intervalos das tensões.

\section{Da composição}

Seria pouco supor a formação de um profissional de saúde como um processo de aquisições e habilidades intelectuais. Além das atividades protocolares, quais intercessores intervêm em nossa formação? Para Ceccim, ${ }^{5}$ intercessores são interferências, constituindo agenciamentos, convocações ou modos de sentir-pensarquerer e, aqui, nos servirão para qualificar os fatores de exposição a que somos apresentados para nos configurarmos profissionais de saúde.

Uma pedagogia pode fazer saber que a língua, como coisa viva que é, só muda quando mudam as pessoas, as relações entre elas e a forma como lidam com o mundo. Falamos então de intercessores capazes de provocar muitos burburinhos, cochichos, sussurros, desde que para outra língua que não sabemos. Deleuze nos traz a ideia de que intercessor pode ser tudo que dá para pensar em determinado campo - na saúde mental coletiva - que lhe é exterior, que lhe está no seu fora.

A pedagoga seduz intercessores que façam gaguejar uma língua maior de disciplinas, que faça gaguejar palavras de um fio condutor, de uma língua maior em saúde mental coletiva. Talvez a pedagoga estrangeira de sua própria língua possa, em intercessões, fazer uso de exercícios de desmanches profundos de frases feitas no campo das ideias em saúde e em educação. 
Intercessores são exercícios de pensamento, são novas formas de expressão, são jeitos diversos de pensamentos gagos. Pensar não é o exercício natural de uma faculdade. O pensamento não pensa sozinho e por si mesmo, como também não é perturbado por forças que Ihe permaneceriam exteriores. Pensar depende necessariamente das forças que se apoderam do pensamento. ${ }^{6: 1220}$

Intercessores são forças. Fazem o pensamento sair de sua imobilidade, provocando encontros. Intercessores nos importam por serem capazes de tornar possível a criação. Ser intercessor em si é romper com o sujeito da oração, inerte. É sofrer a ação de forças externas que nos movimentem. Pensar por intercessão é explicar, desenvolver, decifrar, traduzir palavras. Criar vocábulo. Cada vocábulo de um idioma, cada ideia que ele carrega é uma teia de sentidos que vai se alterando ao longo da História.

Tão falsa quanto real, fica difícil apontar nela onde começa a ficção e quando termina alguma realidade. Obviamente que não estou a falar somente da pedagogia: reconhecemos que é da vida a criação da vida.

Mestiça, a pedagoga. Nunca soube o que Ihe havia acontecido. Ela acontecia: de pouco em pouco, acontecia "do velho cara ou coroa que é afundar ou nadar, recordar ou esquecer, as diferenças que as coisas insignificantes provocam..."7:24 Coisa de mestiça é trans-bordar. É sair da calha comum da palavra. É tecer o corpo e nascer ao mesmo tempo. A pedagoga que se quer mestiça, precisa desencalhar: não há palavra régia em seu transitar. Mestiça de ter novidade para oferecer, de chegar sempre com telhas a menos. Mestiça, de acreditar em explicação de confundir, querer desperdício para poder faltar, viver de inventar palavras de mansinho, bem de leve para não poder caber.
Da derivação

\begin{abstract}
s.f.: Ação de derivar ou de desviar as águas (ou outro fluido) do curso que seguiam. / Gramática: Processo pelo qual as palavras de uma mesma raiz se formam pela mudança de desinência ou afixos. / Matemática: Cálculo de uma derivada. / Medicina: Cada um dos circuitos eletrocardiográficos. ${ }^{8: 194}$
\end{abstract}

A derivação consiste na formação de novas palavras a partir de uma palavra primitiva. Assim, tomemos como ponto de partida as palavras com bases já existentes na tentativa de novas palavras: pode um doido endoidecer doidivanas? 0 amanhã amanhecer amanhecido? A terra enterrar no terraço o horizonte? O louco enlouquecer a loucura? Palavras de base para outras palavras. Quisesse lágrima palavra de emoção líquida escorrendo da língua. Doença palavra pó que num soprar se vai. Sussurros de um pequeno estar só, sem palavras.

Com que palavras nos colocamos a navegar? Em que águas nossos corpos se proporão a banhar? Ao desviar qualquer pensamento, percorrer outras águas, ao ritmo de tantas marés, distraímos a necessidade de informar, a busca por respostas, distraídos deixamo-nos ir com a correnteza. Uma vez no fluxo das marés, não mais uma margem para fixar. Nós liquefazendo palavras possíveis de água. Nós propondo palavras à deriva, em ilhas flutuantes. Derivar para tornar outro que não saberemos, compostos de uma terceira margem que nos atravessa. 


\section{Do ensaio}

Inventei tantas outras para eu ser. De muitas palavras e percursos, fiz-me de outros invencionáticos que, como eu, procuravam imagens em caleidoscópios. Excursiono visitante e temporária estas invenções. Em mim, efeitos de tantas produções: um tanto desassujeitada, percorro beiras de abismos. Interessam-me os abissais, as nebulosas, os buracos-negros, as descidas da ladeira, os seres inanimados, o que é oculto, o impossível me interessa. Se eu desse pé não me ensaiaria.

Assim a pedagogia ensaia: com quais palavras compomos uma cena de saúde mental coletiva? A pedagogia encena um passeio a céu aberto. No passeio, a possibilidade de um modelo melhor do que "a clínica individual de nossas aflições".9:12 Um pouco de horizonte sobre nossas cabeças, uma relação com o exterior: De acordo com a autora, somente uma pedagogia para dar sustentação a esse movimento, pelo seu caráter de coletivo, de cidade, de pensamento, de aprendizados.

A seguir, cenas de uma pedagogia palavrageira em saúde mental coletiva. Contar. Inventar. Recriar. Zombar. Suprimir um ponto, acrescentar vírgulas. Espraiar os campos. Campo é palavra para o espaço do andarilhar do residente transeunte em serviços de desinstitucionalização da saúde mental coletiva. Espaços de andarilhos, tais campos, ora verdes ora concretos, fazem a pedagoga ir mais longe. Uma pedagoga para encenar, em Centros de Atenção Psicossocial (CAPS II e CAPSi), na saúde indígena com a etnia Mbyá Guarani, em Residenciais Terapêuticos, cotidianos lindos de viver.

Cena I: Acontece. Não se sabe muito bem como, mas eles vão que vão! Ou se sabe: a implicação é grande, oscila entre altos e baixos, mas ora acontece. O cenário é a sala de equipe do CAPS. Ali, um mundo de coisas, gestos, palavras, desejos. Desde as paredes a disposição dos móveis, a ligeira bagunça da mesa.... Tudo vibra: o mural de recados e seus papeizinhos falantes, o armário de prontuários que para além de um registro protocolar, abarca histórias de vida. O chimarrão compartilhado em manhãs frias, o planejamento posto em prática, o estudo de caso estudado. Vibram pessoas porque elas têm gana, sempre.

Cena II: Oficina Fora da Casinha. Uma oficina vagante que se dá em bando, em debandada. Encontros que percorrem cantos de uma cidade e abrem espaços para àqueles viventes fazerem-se no fora. A cidade é investida de uma orientação pedagógica expressa em seu modus vivendi, nos cenários, nas ritualizações e nas instituições e, a educabilidade deste fora é uma constante no processo educativo que é a dinâmica urbana da cidade. A Oficina Fora da Casinha é detentora de uma instrução socializadora e investida de uma função pedagógica, por entendermos que esta cidade detém uma função social advinda da experiência da urbanidade.

Cena III: Acompanhamento Terapêutico: É compor trajetos, é fazer-se em processo, é um curso d'água, são obstáculos no caminho, são os ritmos de muitas caminhadas, é estar em muitos e também estar sozinho. Percurso se faz de relações com pessoas, de valorização do trabalho em equipe, se faz da escuta disponível, do riso fácil. Para mim, inscrevo um percurso que se dá em um corpo. "Que corpo? Tenho vários! Tenho um corpo digestivo, tenho um corpo nauseante, um terceiro cefalálgico, e assim por diante: sensual, muscular, humoral, e, sobretudo, emotivo: que fica emocionado, agitado, entregue ou exaltado, ou atemorizado." 3:24 Porque não viemos de longe para nos enganarmos!

Cena IV: Pedagogas a caminho estão sempre incompletas como quem de repente desfaz-se, aprende, compartilha. No caminho como quem de repente cresce, transforma-se, coletiviza-se. Como alguém 
que se compromete na tentativa com o plural, com o entredisciplinar. Estamos mestiças, fazemo-nos "capazes de escapar ao limite disciplinar das profissões e de se expor à alteridade (sem hierarquizações e sem divisões técnicas ou sociais) com os usuários e com a equipe de saúde." 5:277

Cena V: A deriva: "O que é preciso é pluralizar, sutilizar, sem freios." ${ }^{10: 83}$ Paredes o compõem. Demarcações, limites, escrituras. Fronteiras imaginárias, um corpo para caber. Queremos fazer caber? Sem lugar fixo, sem posologia, sem prescrição, na dissolução de diagnósticos, na porosidade de patologias, em espaços e tempos impossíveis de quantificar por metragem ou cronômetros, o acompanhamento terapêutico vagueia entre um dentro e um fora, um fora e outros foras, entre um eu e um mim, entre margens, nas travessias. Dá-se entre a rua e o acompanhado, entre o acompanhante e o acompanhado, entre o acompanhado e ele mesmo, entre qualquer lugar, dois pontos, em curvas e em emaranhados, em linhas, em paralelas, entre cruzamentos.

Ela entre muitos eus e as paredes. Ela também compõe o quarto. Ela e o seu corpo sempre a desejar: o corpo espia a janela, ele sabe que ela pode mais. Ele (o corpo) faz com que ela espie pela janela, seus olhos vagueiam: há encontros, há plurais lá fora. Agora ela também sabe o que o corpo não esquecia: ela se lança como flecha para o alvo e como o alvo para a flecha. Há encontros. Do quarto para a janela, da janela para o portão, do portão para o carro, do carro para o ônibus. No ônibus os fluxos de uma cidade: passar a roleta, desviar do estudante e sua mochila carregada de palavras, sentir os cheiros de todas as gentes, ouvir o murmúrio resultante de tantas vozes, a dureza do som dos parafusos frouxos, ela que se lança ao incerto, ao des[a]tino, ao evento, as encenações, aos [im]possíveis, aos i[ni]magináveis, ela que, em ato, se encena, se desenha, se permite outra. Entretanto, este espaço nem público nem privadocoloca frente olhos difíceis de enxergar, a loucura, o desvio, o estranho, o estrangeiro, o anormal. Ela, de corpo vagante pela cidade, evoca um novo direito de se relacionar: tatear estrelas, gostar das coisas do chão. Ela surpreende, desloca, $f a z$ ver, ajuda a olhar, a se olhar. Ela, mais carne que síndrome, mais coletiva que individual, mais fora que dentro, mais rua que sala, mais trajetos que pousos.

$* * *$

A seguir, cenas de um fabulário cotidiano dos Mbyá Guarani - em unidade básica de saúde de uma tékoa. Fluxo intenso no posto, cachorro, gato, galinha. Dia de vacinação, pré-natal, criancinhas e barbadões. Tratamento de canal, uma extração. Equipe completa, residentes disponíveis - e achando tudo aquilo lindo!

Cena VI: Éramos nós, no barro vermelho jogando futebol, um coletivo. $\mathrm{E}$ eu, sabendo não mais que três palavras em guarani, me apaixonava outra vez. São crianças cooperativas umas com as outras: eu na goleira com mais dois pequenos de no máximo quatro anos, no campinho um time misto onde os meninos maiores, do tipo jogador Neymar, praticavam a lindeza de compartilhar a bola com os demais, articulando o jogo no meio de campo de forma que todos pudessem jogar e assim, de fato, haver uma partida de futebol. Trinta minutos passados e eu, sem ar, tento propor um intervalo: "- Alguém aí está com sede? Que tal bebermos uma água lá no posto?", ideia aceita, coletivo em debandada! Como as pias eram altas, os pequenos não alcançavam as torneiras. Tomo um deles em meus braços, menininho lindo, de rosto craquelado de tanta sujeira. Confesso, não pude me conter: como uma profe no jardim de infância, lavei bem aquele rosto, era verão e pude usar bastante água! E quando 
largo o menino no chão, limpo de morrer, com olhos arregalados, ele me observa de forma muito séria e, imagino eu, tenta entender "o que foi isso que passou por mim?!"

Cena VII: Sementes de coentro doadas por um grande capixaba. Manjericão, hortelã, babosa e temperinho verde vindos diretamente do Centro de Eventos da Pitinga. Nós, com enxadas em punho, preparamos a terra para o plantio. Toda indiarada envolvida: os maiores misturavam composto orgânico na terra, enquanto riam do nosso jeito de branco, embora alguns desconfiem que o Vinícius seja um indígena! Os pequenos tentavam nos ensinar as palavras em guarani para as hortaliças, arbustos e árvores do entorno. Apontavam para um arbusto em específico e empolgados falavam: Pin-tá! Olho para o arbusto, médio porte, bem exótico eu diria, com umas bolas cabeludas avermelhadas penduradas aos montes: A-hãm, legal, pin-ta!"- falo eu com um desânimo próprio de um adulto sedentário. Mas continuaram a repetir Pinta! Pin-ta! Pin-tá! Voltamos para as funções do plantio e logo eles pararam com aquele coro de pequenas vozes. Passados alguns minutos de silêncio, em minha frente, Marianinha exibia um rosto pintado de um laranja avermelhado. Percebo Cristina com desenhos bem delineados nos braços, o menino pintou os olhos. Disse que era um dragão e eu acreditei. Como poderia ser outra coisa? Pin-tá, soubemos na prática, é a palavra guarani para urucum.

Cena VIII: A pedagoga ilustra: gosta de imagem para desmontar palavra. Chega entre a foto que perdura o instante: somos em intervalos de caducar palavra. A imagem deixa toda palavra assim: meio corpo, palavra tinindo, trincando.
Parte II

Na faceirice as palavras me oferecem todos os seus lados.

Então a gente sai a vadiar com elas por todos os cantos do idioma ${ }^{\text {4:133 }}$

Nada é fixo entre linguajares, tudo é procura. Fluxo incessante de palavra, a saúde mental coletiva tem suas vozes, é através delas que atualizam os princípios do Sistema Único de Saúde (SUS), por de palavras tão especiais como universalidade, equidade, integralidade. As políticas de saúde mental são vivas de palavras, dizem da preocupação com o cuidado, fazendo-se debruçar sobre discussões onde as dúvidas em como cuidar são frequentes. Cuidar é também pensar as nossas palavras.

A pedagoga, no esforço do entre, sai a imitar suas palavras, fica a vadiar com elas pelos cantos do idioma da saúde mental coletiva. Eis que, dos encontros e dos afetos, surge a Oficina de Palavras, relicário imenso da pedagoga que pensa palavra.

\section{Oficina de Palavras}

Prática de desmanche de palavras era o que tínhamos em mente. "Dar importância não ao significado, mas à produção. Em vez de perguntar "o que é isto?, perguntar "o que posso fazer com isto? "Em vez de perguntar "é verdade?", perguntar "como funciona?" Não interpretar, mas experimentar. "11:16

Nossa produção não teve definidos objetivo específico nem metodologias. Nossa produção foi processo que se deu em encontros: tentamos algumas linhas convergentes.

A Oficina de Palavras foi produzida em 2011 com pessoas frequentadoras do CAPS II de Viamão. Neste tempo está escrevente 
já pensava escovar palavra. Na modalidade de oficina terapêutica, nosso movimento pôde fazer pensar que são as palavras que nos fazem viventes. Nossos corpos são constituídos de palavras, de discursos, de prescrições, de noções de saúde e de pedagogia. Somos viventes de palavras e nesses falatórios, a oficina ousa a invenção: porque estas palavras e não outras? Toda continuidade é apenas o efeito de uma interpretação. O que temos em vez disso são falhas, quebras, hesitações, movimentos inesperados, arranques e paradas abruptas.

Descontínuos, nossas palavras em muitas direções informaram, proliferaram, gestaram, rotularam. Fizemos caber palavra. Apagamos e inscrevemos outras, ora não deixávamos nada. Mas não conseguimos sujeitos inteiriços, plenos, menos contraditórios. Celebramos o prazer e o perigo da confusão de fronteiras. A incerteza pode ter grande potencial para criação de pensar outros quereres e fazeres terapêuticos neste mental que é tão corpo como uma espinha dorsal.

Iniciada a produção em oficina, nossas palavras começaram a borrar, algumas permaneceram e outras se descompuseram. Privilegiamos nestes espaços de oficina, operações de desmanches. Transformamos nossas palavras, que eram as palavras dos outros sobre nós mesmos em algumas dúvidas: Que palavras nos compunham? Reconheceríamo-nos nestas palavras? $E$ se nos vemos e nos fazemos naquelas palavras, como nos vermos e nos fazermos em outras tantas palavras disponíveis em nosso falatório infindo?

Fazer parte de uma Oficina de Palavras não é desvelar verdades estabelecidas em palavras no passado, ou simplesmente traduzi-las para acalentar inquietações do presente e tão pouco produzir efeitos num futuro. Trata-se de contestar a maneira sobre as quais essas palavras de verdade se fundaram, para que outras palavras e outras formas de escolhê-las se tornem possíveis.
Investir em mudanças no campo subjetivo é combater práticas de assujeitamento que fecham ou esgotam o campo de possíveis, propiciando a criação de outros possíveis ou mesmo do próprio possível, quando o campo parece esgotado.

Exemplo: Manuseio da leitura e afetação do Poema de Viviane Mosé Receita para Lavar Palavra Suja. Em pedaço de tecido, com tinta, escrevíamos a palavra que gostaríamos de lavar. Palavras patológicas, que diziam de diagnósticos inconclusos, foram escritas com tinta guache. Palavras da vida, como saudade e luto, foram pintadas com tinta de tecido. Após costurarmos nossos pedaços de tecidos escritos com nossas palavras à serem lavadas, em tarde de sol escovamos nossas palavras, mergulhamos em balde com água e sabão produção coletiva de pensar palavras.

O resultado foi um tecido em fragmentos costurados onde as palavras doenças pintadas a guache, borraram e se desconfiguraram. Legível mesmo somente as palavras vida. Talvez para dizer que a saudade que sentimos por alguém é de certa forma, permanente: sempre sentiremos saudades de alguém, ou de algo. Já nossas patologias, depressões, quadros clínicos, estes podem ser mudados, sentidos e desmontados, refeitos, repensados, esvaziados, deixados de lado mesmo presentes, transformados: é nossa a criação de noção de saúde.

\section{Parte III}

O dicionário dos meninos registrasse talvez àquele tempo nem do que doze nomes. Posso agora nomear nem do que oito: água, pedras, chão, árvore, passarinhos, rã, sol, borboletas... Não me lembro de outros. ${ }^{4: 85}$ 
A pedagoga toma para si um "dicionário de meninos". Palavras corpo, palavras tópicas, palavras coisas e palavras coletivas. Parlarvas: nascidas de casulo. Talvez nem do que algumas palavras de desmontar, assim práticas de desmanche de palavras podem bem mudar velhos hábitos de informar.

Acolhimento: As acolhidas, (a escuta primeira que se faz à pessoa no CAPS) este cotidiano das pessoas inseridas num fazer que se inclina ao outro, provocamme. Tocam-me os timbres de voz, me movimentam as histórias de vida, fazem-me vibrar pelo som do silêncio em dois. Persigo experiências que se fazem de pensamentos transgressores, que se rebelam num fazer prudente, se implicam com a integralidade do cuidado. Escutar é complicado e sutil. Diz - Alberto Caeiro que "não é bastante não ser cego para ver as árvores e as flores. É preciso também não ter filosofia nenhuma." ${ }^{12:} 75$

Ética: De acordo com Boff, ${ }^{13}$ podemos pensar ethos: ética, em grego; designa a morada humana. O ser humano separa uma parte do mundo para, moldando-a ao seu jeito, construir um abrigo protetor e permanente. A ética, como morada humana, não é algo pronto e construído de uma só vez. O ser humano está sempre tornando habitável a casa que construiu para si. Ético significa, portanto, tudo aquilo que ajuda a tornar melhor o ambiente para que seja uma moradia saudável: materialmente sustentável, psicologicamente integrada e espiritualmente fecunda.

Plano Terapêutico: Este plano é curvilíneo. É emaranhado terapêutico: terapêutico de muitas (outras) dimensões que um plano não permite. Uma ciranda terapêutica! Também em côncavos! O que não quer dizer que não lacemos nossos dados. Sim, os dados foram lançados e neste tempo muito se há de desejar. No lançar dos dados dedos que ficam à espera, longa ou não, de alguma abertura capaz de fazer passar uma vida, um instante, desejos, uma ínfima palavra.
São dedos que ficam à espera de linhas de cuidado neste plano que se anuncia pronto embora torto, inacabado, insuficiente, desajeitado, difícil de caber.

Explico-me: Não é possível traçarmos um plano já que estamos falando de vida e vida é caos. Ora dá, ora não dá. Compomos aqui e ali, nunca sós: no mínimo em dois. Aí, em dois a coisa é do nível do encontro. Encontro é encontro, precisa explicar? A vontade é grande. Os pactos se fazem. Mas onde mesmo é que vamos atar nossos nós? Não sabemos. Tateamos. Inconstantes e provisórias nossas pernas desacreditadas do que são capazes, caminham.

Clínica: Etimologicamente, a palavra clínica remete ao ato de inclinar-se sobre o leito de quem sofre. Porém quem se inclina pretende curar, e uma cura, a despeito da diversidade de sentidos que Ihe sejam atribuídos, jamais podem ser realizadas de modo desinteressado ou neutro. [...] De fato, quando o sofrimento reside na alma, na subjetividade, aquele que se inclina não o faz simplesmente para despojar alguém de suas dores, mas, principalmente, das estratégias de existência associadas a essas dores, engajando todo o ser daquele que sofre. Deste modo, uma cura é algo muito diverso de uma decoupagem: para além da eliminação do sintoma ou do sofrimento, está em questão um novo modo de subjetivar-se.

Profissão: Se a profissão de pedagoga tiver um fim ulterior a si mesma, sustento, reconhecimento, auto realização, conscientização - estará contaminada pelo utilitarismo. Então, fenece. Pois, já se viu um pensador profissional? Os pedagogos potentes preferem ser aficcionados. ${ }^{11}$

Escuta: A palavra tem importância na medida em que a relação dos sujeitos com o desejo está mediada pela linguagem, e nisto estamos todos envolvidos, como seres falantes, como seres viventes. Assim, a noção de escuta deve estar vinculada à ideia de cuidado, com o objetivo de abrir 
um espaço para a palavra e a produção do louco. Cuidado que muitas vezes recai numa prática moral educativa, uma vez que "cuidar" já pressupõe "o outro" como alguém que precisa de "nossos cuidados". Penso que seria importante comprometer o cuidado na perspectiva da escuta, o que deve implicar necessariamente, para nós, cuidar da nossa própria palavra no sentido de livrá-la dos preconceitos e de mantê-la aberta às expressões do inconsciente.

Problema: A moral da criação e a moral da domesticação são plenamente digna uma da outra, no que concerne os meios de se impor. Podemos apresentar como princípio mais elevado o seguinte: para levar a termo a moral é necessário ter a vontade incondicionada do contrário. Este é o grande problema, o problema sinistro, ao qual consegui mais longamente: a psicologia dos "melhoradores" da humanidade. Um fato diminuto e no fundo modesto, este da assim chamada pia fraus, abriu-se um primeiro acesso a este problema. A pia fraus foi a herança de todos os filósofos e sacerdotes que "melhoraram" a humanidade. [...]. Eles duvidaram de direitos totalmente diversos... Expresso em uma fórmula, poder-se-ia dizer: "todos os meios, através dos quais até aqui a humanidade deveria se tornar moral foram fundamentalmente imorais." ${ }^{14: 55}$

Subjetividade: De uma maneira ou de outra, todos nós estamos implicados em processos de produção subjetiva, como máquinas de guerra a minar a armadilha de um "eu" interiorizado que sustenta práticas supostamente "individuais" de cuidado e atenção. A questão está em inventar modalidades clínicas de muitas saídas para a pluralização do potencial desejante das singularidades, nosso potencial de crítica e de revolta. A expressão da palavra 'produção de subjetividade' denota a necessidade de ativar coletividades.
Parte IV

Entre conversas com amigos, o tema educação e saúde sempre vieram à tona. Em espaços formais e em mesas de bar colocamo-nos a pensar sobre nossas inserções em serviços de saúde, em escolas, espaços de gestão. Somos professores e pedagogos, enfermeiros e educadores físicos, historiadores e psicólogos curiosos do exercício de também escovar palavras, de também fazer gaguejar conceitos. Expressão que gostei desses encontros entre amigos foi de uma pedagoga professora na educação infantil: "- Engraçado, tudo que é terapêutico pra vocês, é pedagógico pra mim!".

Nunca havia visto tanta facilidade em trocar palavras de lugar, em misturar conceitos, em borrar certezas. Fiquei a escovar esta frase. Convivi com ela durante muito tempo, afinal, não me é obvio tais distinções e nem sei se acredito que haja: o terapêutico e o pedagógico, palavras eternizadas em pedras de quebrar perna? Hoje penso que estar preocupada em definir quais palavras são mais terapêuticas ou mais pedagógicas não faz sentido. Terapêutico e Pedagógico não dizem mais nada, estão cheios de informar. Talvez se lavarmos tais palavras, misturá-las em azul anil, talvez.

Quebrar palavras é quebrar práticas de saúde mental que acontecem em torno da confissão: Como escreve Foucault, ${ }^{15}$ a obrigação de fazer passar regularmente pelo fio da linguagem o mundo minúsculo do dia a dia, das falhas banais, as fraquezas mesmo imperceptíveis, até o jogo perturbador dos pensamentos, das intenções e dos desejos; ritual de confissão.

Nossas práticas são nossos caminhos. Assim, quebrar pernas é quando uma pessoa usuária do serviço de saúde mental sabe exatamente quais palavras usar para conseguir aquele remédio ou tal laudo para perícia na previdência social. Este lugar 
certo de palavras chave, fáceis de caber confessa: não sabe brincar de palavras mais do que trabalhar com elas. A pedagoga propõe quebrar palavra para que esse tudo confessar em saúde mental possa ser tropeço de abrir olhos: e a gente vai continuar dizendo tudo?

Antes de palavrar, o silenciolhar. A-signifixar. Desmanche de palavra só serve para deixar vazio espaços de dizer la-ra-lá... lá-ra. Burburinho de inventar latido. Grilo de choro cri-cricando o bem fazer. Palavra de louco fazendo gaguejar nossa saúde mental coletiva. Novas expressões de silenciar. Espaço vazio de palavra é mistério de gente diversa.

\section{Epílogo}

O prazer da palavra é o momento em que meu corpo adquire seu próprio linguajar. Porque meu corpo não tem as mesmas palavras que eu. Ele diz sem mim. O prazer da palavra no corpo é desvio de águas que segundo Barthes "deriva toda vez que eu não respeito o todo e que, à força de parecer arrastado aqui e ali, ao sabor das ilusões, seduções e intimidações da linguagem, qual uma rolha sobre as ondas, permaneço imóvel, girando em torno da fruição intratável que me liga ao texto (ao mundo). Há deriva, toda vez que a linguagem social, o socioleto, me falta". ${ }^{3: 26}$

Falta-me a linguagem adequada, faltame a capacidade de bem informar, faltame a coragem para quase tudo explicar. Recusa da utilidade das coisas? Então eu não sei como as coisas andam? Pensar nossas palavras, escovar sílaba por sílaba pelo prazer do desmanche de fonemas sons de ritmos e o aparecimento de vazios de ecoar silêncios, é potência de coletivos e na multiprofissionalidade em saúde mental coletiva, saber que as palavras sofrem decomposição por gosto.

A pedagoga intui que, em processos de composição, derivação e ensaio de palavras, é possível um gaguejar de conceitos e práticas em saúde mental coletiva, onde outras línguas podem fazer desinstitucionalizar palavras de aprisionar.

Jeito simples para dizer que as palavras da saúde mental coletiva não são elementos fixos entre línguas, em práticas de saúde multiprofissionais. Nossas palavras não são ingênuas e não dependem de uma lógica de entendimento: nossas palavras são derivas. Qualquer coisa sem lugar, sem fixação. Qualquer movimento sem língua. Nenhuma mentalidade. Nenhuma palavra.

A produção de atos terapêuticos em equipes multiprofissionais desafia nossa estrutura de pensar práticas especialistas de cuidado. Esvaziar palavra é possibilitar atos de saúde em outras perspectivas que, diferente de paradigmas, servem para tirar da ponta da língua nossas palavras colocadas em prática para estabelecer o cuidado com o outro, colocando-nos ativos nos processos de mestiçagem, como intercessores.

Uma vez no lugar mestiço, que inventar palavras devolva a alteridade do usuário, palavra que experimente em equipe a novidade, palavra que afirme a vida, palavra que traduza o "cuidado, tratamento e escuta como potências de invenção, como critério dos valores de atenção à saúde, como constituição de sentidos expansivos da vida e das aprendizagens para autoprodução de si e do mundo (...)". 5:277 


\section{Artigo Original}

\section{Referências}

1. Bondía J, Larosa. Notas sobre experiência e saber de experiência. Campinas, FEMEC; 2001.

2. Deleuze G, Guattari F. Mil Platôs - capitalismo e esquizofrenia 2a. ed. São Paulo: Ed. 34; 2008. v.5.

3. Barthes R. O Prazer do texto. São Paulo: Perspectiva; 2010.

4. Barros M. Memórias Inventadas: As Infâncias de Manoel de Barros. São Paulo: Planeta do Brasil; 2008.

5. Ceccim R. Equipe de saúde: a perspectiva entre-disciplinar na produção de atos terapêuticos. In: Pinheiro R, Mattos RA (org). Cuidado: as fronteiras da integralidade. Rio de Janeiro: CEPESC/ UERJ, ABRASCO; 2008. p. 276-278.

6. Vasconcellos J. A Filosofia e seus Intercessores: Deleuze e a não-filosofia. Educ Soc, Campinas. 2005; 26 (93):1217-1227.

7. Woolf V. Objetos Sólidos. São Paulo: Siciliano; 1992.

8. Ferreira ABH. Miniaurélio: o dicionário da língua portuguesa. Curitiba: Positivo; 2010.

9. Fagundes S. A integralidade e a Saúde Mental: Projeto de qualificação da atenção em saúde mental nos âmbitos do cuidado técnico e profissional. In: Ministério da Saúde. Secretaria de Atenção à Saúde(BR). Brasília: Ministério da Saúde; 2013. (Cadernos de Atenção Básica, n. 34).

${ }^{10}$ Barthes R. Roland Barthes por Roland Barthes. São Paulo: Estação Liberdade; 2003.

${ }^{11}$ Corazza S. Silva, T. T. Composições. Belo Horizonte: Autêntica; 2003.

${ }^{12}$ Pessoa F. Poemas de Alberto Caeiro. 10a.ed. Lisboa: Ática; 1993.

${ }^{13}$ Boff L. A Águia e a Galinha: uma metáfora da condição humana. Petrópolis (Brasil): Vozes; 1997.

${ }^{14}$ Nietzsche F. Humano, Demasiado Humano. Um livro para espíritos livres. São Paulo, Cia. das Letras; 2002.

${ }^{15}$ Foucault M. A vida dos homens infames. In: Foucault M. Estratégia, poder-saber. Ditos e escritos IV. Rio de Janeiro: Forense Universitária; 2003. 